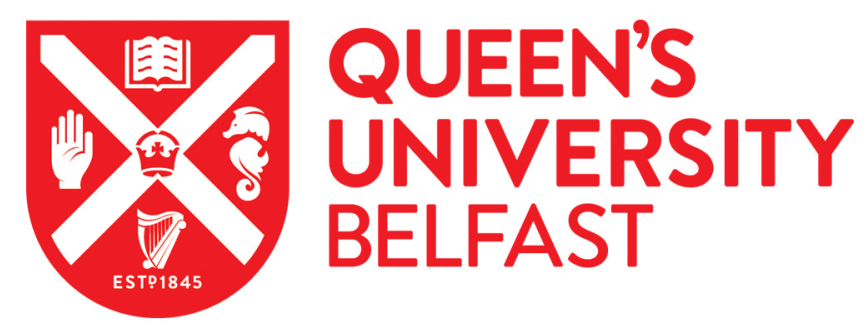

\title{
Rapidly dissolving bilayer microneedle arrays - A minimally invasive transdermal drug delivery system for vitamin B12
}

Ramoeller, I., Tekko, I., McCarthy, H., \& Donnelly, R. (2019). Rapidly dissolving bilayer microneedle arrays - A minimally invasive transdermal drug delivery system for vitamin B12. International Journal of Pharmaceutics. https://doi.org/10.1016/j.jpharm.2019.05.066

Published in:

International Journal of Pharmaceutics

Document Version:

Peer reviewed version

Queen's University Belfast - Research Portal:

Link to publication record in Queen's University Belfast Research Portal

Publisher rights

Copyright 2019, Elsevier.

This work is made available online in accordance with the publisher's policies. Please refer to any applicable terms of use of the publisher.

\section{General rights}

Copyright for the publications made accessible via the Queen's University Belfast Research Portal is retained by the author(s) and / or other copyright owners and it is a condition of accessing these publications that users recognise and abide by the legal requirements associated with these rights.

Take down policy

The Research Portal is Queen's institutional repository that provides access to Queen's research output. Every effort has been made to ensure that content in the Research Portal does not infringe any person's rights, or applicable UK laws. If you discover content in the Research Portal that you believe breaches copyright or violates any law, please contact openaccess@qub.ac.uk. 


\section{Accepted Manuscript}

Rapidly dissolving bilayer microneedle arrays - A minimally invasive transdermal drug delivery system for vitamin B12

Inken K. Ramöller, Ismaiel A. Tekko, Helen O. McCarthy, Ryan F. Donnelly

PII: S0378-5173(19)30425-9

DOI: https://doi.org/10.1016/j.ijpharm.2019.05.066

Reference: IJP 18396

To appear in: $\quad$ International Journal of Pharmaceutics

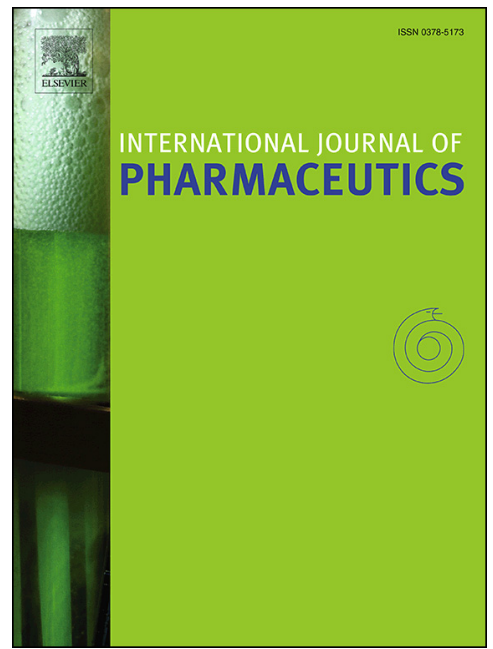

Received Date: $\quad 10$ April 2019

Revised Date: $\quad 24$ May 2019

Accepted Date: $\quad 27$ May 2019

Please cite this article as: I.K. Ramöller, I.A. Tekko, H.O. McCarthy, R.F. Donnelly, Rapidly dissolving bilayer microneedle arrays - A minimally invasive transdermal drug delivery system for vitamin B12, International Journal of Pharmaceutics (2019), doi: https://doi.org/10.1016/j.ijpharm.2019.05.066

This is a PDF file of an unedited manuscript that has been accepted for publication. As a service to our customers we are providing this early version of the manuscript. The manuscript will undergo copyediting, typesetting, and review of the resulting proof before it is published in its final form. Please note that during the production process errors may be discovered which could affect the content, and all legal disclaimers that apply to the journal pertain. 
Rapidly dissolving bilayer microneedle arrays - A minimally invasive transdermal drug delivery system for vitamin B12

Inken K. Ramöllera, Ismaiel A. Tekkoa,b, Helen O. McCarthya and Ryan F. Donnellya*

a School of Pharmacy, Queen's University Belfast, Medical Biology Centre, 97 Lisburn Road, Belfast, BT9 7BL, United Kingdom

${ }^{b}$ Department of Pharmaceutics and Pharmaceutical Technology, Faculty of Pharmacy, Aleppo University, Aleppo, Syria

*Corresponding author:

Professor Ryan F. Donnelly

Chair in Pharmaceutical Technology

School of Pharmacy

Queens University Belfast

Medical Biology Centre

97 Lisburn Road

Belfast

BT9 7BL, Northern Ireland

United Kingdom

Tel: +44 (0) 2890972251

Fax: +44 (0) 2890247794

Email: r.donnelly@qub.ac.uk 


\section{Abstract}

Vitamin B12 plays an essential role in one-carbon metabolism in the human body. A deficiency in this vitamin can lead to severe haematopoietic and neuropsychiatric disorders and is currently treated by oral or parenteral administration of exogenous vitamin. Unfortunately, the absorption of orally taken vitamin B12 is low and highly variable, while injections can cause pain and anxiety. Thus, an efficient alternative drug delivery system for overcoming these shortcomings is highly desirable. Novel polymeric microneedle (MN) arrays have the potential for minimally invasive transdermal treatment of vitamin B12 deficiency. Bilayer dissolving MN arrays (19 x 19 needles, $600 \mu \mathrm{m}$ height) containing $135 \mu \mathrm{g}$ vitamin B12 were cast using two different aqueous polymer blends. MN arrays showed sufficient mechanical strength for skin insertion, dissolved rapidly and delivered $72.92 \%$ of their drug load in vitro over $5 \mathrm{~h}$. Ultimately, the potential of delivering a therapeutically relevant dose of vitamin B12 transdermally was demonstrated in vivo in Sprague-Dawley rats by comparison to subcutaneous injections. Maximum plasma levels of $0.37 \mu \mathrm{g} / \mathrm{mL}$ occurred $30 \mathrm{~min}$ post-MN application, highlighting the ability of fabricated MN arrays to rapidly deliver vitamin B12 transdermally.

Abbreviations: MN, microneedle; PVP, poly(vinylpyrrolidone); PBS, phosphate-buffered saline; RPHPLC, reverse phase high performance liquid chromatography; ICH, International Conference on Harmonisation; LOQ, limit of quantification; LOD, limit of detection

\section{Keywords}

transdermal; dissolving; microneedle; vitamin B12; bilayer; poly(vinylpyrrolidone); pharmacokinetic 


\section{Introduction}

Vitamin B12 (MW 1355.4 Da) is a water soluble vitamin also known as cobalamin, which is found in animal products such as meat and milk. Provided with a balanced diet, the recommended daily intake of $2.4 \mu \mathrm{g}$ of this vitamin can easily be reached by healthy adults (Institute of Medicine, 1998). However, if a diet is based mainly on vegetables due to limited availability of animal products or religious or cultural beliefs, an insufficient supply of vitamin B12 is likely and will lead to a deficiency (de Benoist, 2008). Also, while a small amount of the vitamin can be absorbed passively, most of it is actively absorbed in the terminal ileum, with intrinsic factor being essential for this process. Consequently, conditions such as ileal resection or a depletion of intrinsic factor, which is often found in elderly people, can result in malabsorption of the vitamin (Lachner et al., 2012).

Vitamin B12 deficiency affects millions of people around the world and may be considered as a public health problem (Guney et al., 2016). Whilst a restricted dietary intake of vitamin B12 is the most common reason for a deficiency in poor countries, with a reported prevalence of up to $80 \%$ in some populations, decreased absorption is a central cause of deficiency among the wealthier populations of the world, especially elderly people (Andrès et al., 2004; Allen, 2009). Taking into consideration that the population aged over 60 years is growing faster than any other age group, an increase in the numbers of people with vitamin B12 deficiency can be expected (United Nations, 2017).

One of the active forms of vitamin B12 is methylcobalamin, which acts as a cofactor of methionine synthase and is essential for one-carbon metabolism. A deficiency can lead to haematological and neuropsychiatric symptoms, such as megaloblastic anaemia and polyneuropathy (Andrès et al., 2004). It has also been associated with conditions like dementia and depression. While haematopoietic disorders can normally be reversed by supplementation of vitamin B12, neuropsychiatric symptoms are often irreversible (Andrès et al., 2004). A deficiency should, therefore, be avoided or treated immediately. 
Nowadays, vitamin B12 deficiency is mostly treated by subcutaneous or intramuscular injections of cyanocobalamin (Fig. 1). According to the guidelines of the British Journal of Haematology, patients should initially receive an intramuscular injection of $1000 \mu \mathrm{g}$ vitamin B12 three times a week for at least two weeks until symptoms are improved (Devalia et al., 2014). While a deficiency caused by dietary shortcomings can be prevented by oral substitution of vitamin B12, plasma levels in individuals with limited absorption have to be maintained by injection of $1000 \mu \mathrm{g}$ vitamin B12 every two to three months (Devalia et al., 2014). Alternatively, a high dose (1000-2000 $\mu \mathrm{g}$ ) of vitamin B12 can be administered orally on a daily basis but only $1.2 \%$ of the dose is absorbed passively which can lead to treatment failure (Devalia et al., 2014; Vidal-Allabal et al., 2016). Excess administration of vitamin B12 is not associated with adverse effects as it is rapidly eliminated renally (Institute of Medicine, 1998). Conversely, intramuscular injections have to be administered by skilled personnel. Additionally, they do not only often cause pain and anxiety in patients, but can also lead to complications, such as haematoma, bleeding and nerve injuries if applied incorrectly (Ogston-Tuck, 2014). Considering this and the above mentioned drawbacks of orally administered vitamin B12, the development of an alternative drug delivery system is highly desirable.

Microneedle (MN) arrays are a minimally invasive and easy to handle alternative to injections (Larrañeta et al., 2016). They can be easily self-administered by the patient (Ripolin et al., 2017) and successful use and likely acceptability by elderly people have already been demonstrated (Quinn et al., 2017). A wealth of published studies have proven that this novel drug delivery system can deliver a variety of low and high molecular weight drugs via the transdermal route by actively piercing through the stratum corneum, thus, overcoming the skin barrier (Edens et al., 2015; GonzálezVázquez et al., 2017; Hutton et al., 2018; Ling \& Chen, 2013; Matsuo et al., 2012; McCrudden et al., 2014; McCrudden et al., 2015; Migalska et al., 2011; Sullivan et al., 2010). The MN-derived drug payload is then delivered into the viable skin layers. 
$\mathrm{MN}$ assisted transdermal delivery of vitamin B12 could provide an excellent alternative to currently used drug delivery systems. If successful, this may lead to a considerable reduction in the numbers of people living with a vitamin B12 deficiency, as a consequence of higher acceptability of this new treatment option, when compared to current approaches. The present study explores the possibility of developing biocompatible dissolving polymeric $\mathrm{MN}$ arrays for transdermal delivery of a therapeutically relevant dose of vitamin B12 to potentially treat and prevent vitamin B12 deficiency. For this purpose, bilayer MN arrays with drug loaded in the MN shafts only were fabricated, characterised and tested in vitro and in vivo for delivery of vitamin B12.

\section{Materials and Methods}

\subsection{Materials}

Plasdone $^{\mathrm{TM}} \mathrm{K}-29 / 32$ (poly(vinylpyrrolidone) (PVP, MW $58 \mathrm{kDa}$ ) and Plasdone ${ }^{\mathrm{TM}} \mathrm{K}-90$ D (PVP, MW 360 kDa) were donated by Ashland (Kidderminster, UK). Vitamin B12 (cyanocobalamin, purity > 98\%) was purchased from Alfa Aesar (Heysham, UK). Cytamen ${ }^{\circledR} 1000$ micrograms $/ \mathrm{mL}$ Solution for Injection was purchased from RPH Pharmaceuticals AB (Haninge, Sweden) and Heparin Sodium (200 units in 2 $\mathrm{mL}$ ) from Wockhardt UK Ltd (Wrexham, UK). All other chemicals used were of analytical reagent grade.

\subsection{Fabrication of dissolving bilayer $M N$ arrays}

Vitamin B12 MN arrays were prepared in two steps from two different aqueous polymer blends. For MN shafts, 2.5\% (w/w) vitamin B12 and 30\% (w/w) PVP (MW $58 \mathrm{kDa})$ were dissolved in deionised water:ethanol $(80: 20, \mathrm{v} / \mathrm{v})$. Approximately $100 \mathrm{mg}$ of the blend was poured into $\mathrm{MN}$ moulds $(19 \times 19$ needles). A square piece of cellulose filter paper (Whatman ${ }^{\mathrm{TM}}$, Little Chalfont, UK) was placed on top of the formulation to spread it evenly and $M N$ moulds were wrapped in Parafilm $M^{\circledast}$ (Bemis Company Inc., Soignies, Belgium), to prevent premature drying. After centrifugation at $5000 \mathrm{rpm}$ for 
15 min, Parafilm $\mathrm{M}^{\circledR}$, filter paper and excess formulation were removed carefully. The first MN layer was dried at room temperatur under protection from light for $4 \mathrm{~h}$. For MN baseplates, drug-free aqueous hydrogels of PVP (MW $360 \mathrm{kDa}$ ) were prepared at various concentrations (15\%, 40\%, 50\%, $\mathrm{w} / \mathrm{w}$ ). Approximately $250 \mathrm{mg}$ of the hydrogel formulations were poured into MN moulds, on top of the initial dried layer and these were centrifuged at $3500 \mathrm{rpm}$ for $15 \mathrm{~min}$. After drying for $18 \mathrm{~h}$ at room temperature under protection from light, $\mathrm{MN}$ arrays were demoulded and sidewalls removed using a pre-heated scalpel. MN arrays were inspected visually using a Leica EZ4W stereo microscope with an integrated camera (Leica Microsystems, Milton Keynes, UK) and a Tabletop TM 3030 scanning electron microscope (Hitachi, Tokyo, Japan). They were stored in a plastic box wrapped in aluminium foil at room temperature until further use.

\subsection{Determination of $M N$ insertion and mechanical strength}

A TA.XT2 Texture Analyser (Stable Micro Systems, Haslemere, UK) in compression mode was used to determine insertion characteristics into an artificial skin model and mechanical strength of bilayer MN arrays following a method developed and validated by Larrañeta et al. (2014). Briefly, MN arrays were attached to the cylindrical probe (cross-sectional area $1.5 \mathrm{~cm}^{2}$ ) of the Texture Analyser and this was moved vertically downward at a speed of $1.19 \mathrm{~mm} / \mathrm{s}$ onto the artificial skin model consisting of eight Parafilm M ${ }^{\circledast}$ layers (Larrañeta et al., 2014). A force of $32 \mathrm{~N}$ per array was applied for $30 \mathrm{~s}$ before $\mathrm{MN}$ arrays were moved upward again. Parafilm $\mathrm{M}^{\circledR}$ layers were separated and holes created in each layer were counted using the microscope. Mechanical strength of MN arrays was evaluated using a similar set up (speed $1.19 \mathrm{~mm} / \mathrm{s}$, force $32 \mathrm{~N} /$ array) but compressing $\mathrm{MN}$ arrays against a flat aluminium surface instead of a skin-simulant for $30 \mathrm{~s}$. Length of individual MN tips was measured before and after compression using the stereo microscope. Percentage reduction of $\mathrm{MN}$ heights was calculated and reported as mean $\pm S D, n=6$. 


\subsection{Evaluation of $M N$ in-skin dissolution kinetics}

In-skin dissolution kinetics of dissolving MN arrays were evaluated using full-thickness neonatal porcine skin. This is a widely accepted skin model for human skin due to its similarities in terms of general structure, thickness, hair follicle content, pigmentation, collagen and lipid composition (Summerfield et al., 2014). Skin samples were obtained from stillborn piglets. These were stored immediately after birth at $-20^{\circ} \mathrm{C}$ and thawed for two days before being skinned. Full-thickness skin was cut into pieces and stored at $-20^{\circ} \mathrm{C}$ until further use. Skin samples were equilibrated in phosphate-buffered saline (PBS, pH 7.4) for 30 min and shaved prior to use. Each sample was placed on tissue paper soaked in PBS to maintain skin hydration and pinned to a Styrofoam ${ }^{\mathrm{TM}}$ platform wrapped in aluminium foil. MN arrays were inserted manually into the skin using a $1 \mathrm{~mL}$ syringe plunger. After applying pressure for $30 \mathrm{~s}$, a $5.0 \mathrm{~g}$ stainless-steel cylinder was placed on top of $\mathrm{MN}$ arrays, keeping them in place. MN arrays were removed after $30 \mathrm{~s}, 60 \mathrm{~s}$ and $120 \mathrm{~s}$ and the degree of dissolution was inspected under the stereo microscope.

\subsection{Determination of vitamin B12 content in MN arrays}

For evaluation of the total content of vitamin B12 in MN shafts, an accurate volume of the formulation was weighed and the density calculated dividing mass by volume. Furthermore, the volume of the conical MN shafts within one array was determined, based upon needle length and width. The total vitamin B12 content was then calculated by multiplying the relative drug content of the formulation by its density and the volume of all MN shafts within one array.

\subsection{HPLC assay development and validation}

For the quantification of vitamin B12 in in vitro and in vivo sample matrices, a reverse phase high performance liquid chromatography (RP-HPLC) method was developed by modifying a published assay (Vigbedor et al., 2015). Analysis was performed on an Agilent 1220 Infinity LC system (Agilent 
Technologies UK Ltd., Stockport, UK) with a Phenomex ${ }^{\circledR}$ Kinetex $^{\circledR} 5 \mu \mathrm{m}$ C18 100 Å column $(150$ x 4.6 $\mathrm{mm}$; Phenomenex, Cheshire, UK) and UV detection at $362 \mathrm{~nm}$. The column temperature was maintained at $25^{\circ} \mathrm{C}$. Separation was obtained at a flow rate of $0.6 \mathrm{~mL} / \mathrm{min}$ with deionised water:methanol $(72: 28, \mathrm{v} / \mathrm{v})$ as a mobile phase and a run time of $7 \mathrm{~min}$ per sample. The injection volume was $20 \mu \mathrm{L}$ for in vitro and $70 \mu \mathrm{L}$ for in vivo sample matrices. The RP-HPLC method was developed and validated according to the guidelines of the International Conference on Harmonisation (ICH 2005). Specificity was shown by comparing chromatograms of blank and spiked samples. Inter- and intra-day accuracy and precision were investigated and limit of quantification (LOQ) and limit of detection (LOD) were calculated based on the residual standard deviation of the regression line.

\subsection{Sample preparation}

In vitro samples were centrifuged at $14,800 \mathrm{rpm}$ for $5 \mathrm{~min}$ prior to RP-HPLC analysis. To separate plasma from blood, blood samples were centrifuged at $2000 \mathrm{rpm}$ for $15 \mathrm{~min}$ at $4^{\circ} \mathrm{C}$ in a refrigerated centrifuge (Sigma 2-16K, Osterode am Harz, Germany). For protein precipitation, a volume of $0.5 \mathrm{~mL}$ methanol was added to $100 \mu \mathrm{L}$ plasma and vortexed for $10 \mathrm{~min}$. After centrifugation at $12,358 \mathrm{rpm}$ for $10 \mathrm{~min}$ at $4^{\circ} \mathrm{C}$, the supernatant was transferred to a glass culture tube. To achieve optimum extraction, this procedure was repeated and the second supernatant was also added to the glass culture tube. A Zymark TurboVap ${ }^{\circledR}$ LV Evaporator Workstation (McKinley Scientific, Sparta, NJ, USA) was then used for drying the extracts under streaming nitrogen over $50 \mathrm{~min}$ at $35^{\circ} \mathrm{C}$. Samples were reconstituted in $100 \mu \mathrm{L}$ deionised water and centrifuged at $12,358 \mathrm{rpm}$ for $15 \mathrm{~min}$ at $4^{\circ} \mathrm{C}$ prior to RPHPLC analysis.

\subsection{In vitro permeation study}

Transdermal permeation of vitamin B12 across dermatomed neonatal porcine skin from dissolving $\mathrm{MN}$ arrays was investigated in vitro using a modified Franz-cell apparatus set up, as described 
previously (McCrudden et al., 2014). Skin was obtained as explained above, but using an Integra ${ }^{\circledR}$ Padgett ${ }^{\circledR}$ Electric Slimline Dermatome (Integra ${ }^{\circledR}$ LifeSciences Corporation, Plainsboro, New Jersey) for trimming the skin to a thickness of $350 \mu \mathrm{m}$ (Garland et al., 2012). The shaved skin was attached to the donor compartment of each cell with the stratum corneum facing upwards, using cyanoacrylate glue (Loctite ${ }^{\circledR}$, Dublin, Ireland). Donor compartments were placed upon a sheet of dental wax covered in aluminium foil and MN arrays were inserted into the skin using a $1 \mathrm{~mL}$ syringe plunger applying firm pressure for $30 \mathrm{~s}$. To secure them in place, a $5.0 \mathrm{~g}$ stainless-steel cylinder was placed on top of MN arrays. Donor compartments were attached to receiver compartments containing $12 \mathrm{~mL}$ PBS ( $\mathrm{pH} 7.4$ ), thermostatically maintained at $37 \pm 1^{\circ} \mathrm{C}$ and stirred with a magnetic stir bar at $600 \mathrm{rpm}$. To prevent evaporation, Franz-cells were wrapped in Parafilm $\mathrm{M}^{\circledR}$. At predetermined time points, $300 \mu \mathrm{L}$ samples were withdrawn using $1 \mathrm{~mL}$ syringes attached to $8 \mathrm{~cm}$ needles and replaced with an equal volume of PBS. Samples were analysed using the validated HPLC method and a vitamin B12 permeation profile was constructed.

\subsection{In vivo study}

Ethical permission for all in vivo experiments was obtained from the Queen's University Belfast, Biological Services Unit (BSU) and all researchers carrying out the work held Personal Licences from the UK Home Office. All in vivo experiments were conducted according to the policy of the federation of European Laboratory Animal Science Associations and the European Convention for the protection of vertebrate animals used for experimental and other scientific purposes, with implementation of the principles of the 3Rs (replacement, reduction, and refinement).

Female Sprague-Dawley rats weighing $221.25 \pm 26.94 \mathrm{~g}$ were used in this experiment. The rats were acclimatised to laboratory conditions for at least 7 days prior to the commencement of experiments. The animals were separated into two cohorts. The control cohort $(n=6)$ received a subcutaneous injection with a volume of $200 \mu \mathrm{L}$ containing $200 \mu \mathrm{g}$ vitamin B12. Blood samples were taken at 
designated time points $(0.5,1,2,3,24 \mathrm{~h})$ via tail vein bleeds, subdividing the control cohort into two sampling time point groups to facilitate frequency of blood sampling.

In the second group of rats $(n=9)$, the test cohort, the animals were anaesthetised under gas anaesthesia (2-4\% isoflurane in oxygen) and the hair on the backs of the animals was removed using a shaver and hair removal cream, prior to application of MN arrays. Four MN arrays (total patch size $1.44 \mathrm{~cm}^{2}$ ) were applied to the back of each animal with firm finger pressure. MN arrays were secured in place for $24 \mathrm{~h}$ with Microfoam ${ }^{\text {TM }}$ Surgical Tape (3 M, Bracknell, UK), an occlusive layer of Tegaderm $^{\mathrm{TM}}$ (3 M, St Paul, Minnesota, USA) and Micropore ${ }^{\mathrm{TM}}$ Surgical Tape (3 M, Wroclaw, Poland), which was wrapped around the animals. The test cohort of rats was subdivided into three sampling time point groups to facilitate frequency of blood sampling, with blood samples taken at $0.5,0.75,1$, $2,3,6,24$ and $30 \mathrm{~h}$.

\section{Results}

\subsection{Characteristics of dissolving bilayer MN arrays}

Upon visual inspection using the stereo microscope, each MN array showed 361 conically shaped needles measuring heights of $600.33 \pm 2.94 \mu \mathrm{m}(n=6)$ and widths of $300.17 \pm 2.04 \mu \mathrm{m}(n=6)$ at the base (Fig. 2A, 1B). Scanning electron microscopy displayed clearly formed sharp needles across the whole array (Fig. 2D).

At first, MN arrays were prepared using an aqueous blend of $15 \%(w / w)$ high molecular weight PVP for casting the baseplates as this concentration had been previously used by Thakur et al. (2016), forming mechanically strong baseplates. However, after centrifugation, diffusion of vitamin B12 from $\mathrm{MN}$ shafts into the $\mathrm{MN}$ baseplate was observed (Fig. 2E). To prevent this, the concentration of PVP was subsequently increased to $40 \%$ (w/w) (Fig. 2F) and then to $50 \%$ (w/w) (Fig. 2G). Only MN arrays with baseplates prepared from an aqueous blend of $50 \%(w / w)$ PVP showed no signs of diffusion upon visual inspection and were, therefore, taken forward in all subsequent studies. 


\subsection{Determination of $M N$ insertion and mechanical strength}

To evaluate the insertion capabilities of fabricated MN arrays, they were inserted into an artificial skin model consisting of eight Parafilm $\mathrm{M}^{\circledR}$ layers (Larrañeta et al., 2014), showing the ability to pierce the first three layers. The first layer was pierced by $99.8 \pm 0.3 \%$ of the $361 \mathrm{MN}$ shafts located on one array, the second by $95.1 \pm 1.4 \%$ and the third by $20.4 \pm 8.6 \%$. The percentage of holes created in each Parafilm $\mathrm{M}^{\circledR}$ layer is presented in Fig. 3. Considering an average thickness of $127 \mu \mathrm{m}$ for each layer, MN shafts inserted down to $381 \mu \mathrm{m}$, which equals approximately $63.5 \%$ of the total needle length of $600 \mu \mathrm{m}$ and is similar to results obtained in previous studies (Larrañeta et al., 2014). Compressing $\mathrm{MN}$ arrays against a flat aluminium surface resulted in a percentage reduction of $\mathrm{MN}$ shafts in height of $2.5 \pm 2.0 \%(n=6)$, indicating high mechanical strength (Fig. $2 B, C$ ).

\subsection{Evaluation of $M N$ in-skin dissolution kinetics}

The rapid dissolution process of MN shafts post-insertion into full-thickness neonatal porcine skin is shown if Fig. 4. Dissolution commenced within seconds of insertion, with more than $50 \%$ of $\mathrm{MN}$ shafts dissolved after only 30 s. All MN shafts were completely dissolved within $120 \mathrm{~s}$ of application.

\subsection{Determination of vitamin $B 12$ content in $M N$ arrays}

A common practice for determining the drug content of dissolving $\mathrm{MN}$ arrays is to dissolve the whole array in a predefined volume of an aqueous medium and to then measure the resulting concentration using a validated analytical technique. In the present study this technique would have led to falsely high drug content due to traces of vitamin B12 in the baseplate. Therefore, an alternative method was used to give a more precise estimation. The density of the formulation used for casting the $\mathrm{MN}$ shafts was calculated to be approximately $1.05 \mathrm{mg} / \mathrm{mm}^{3}$. Multiplication of the density by the total volume of $5.11 \mathrm{~mm}^{3}$ of all $361 \mathrm{MN}$ shafts per array and the concentration of 
vitamin B12 within the formulation resulted in a total amount of $135 \mu \mathrm{g}$ vitamin B12 per $19 \times 19 \mathrm{MN}$ array.

\subsection{HPLC assay development and validation}

One HPLC calibration graph each for in vitro and in vivo sample matrices was generated. The method was specific for vitamin B12 in both matrices, as at the retention time $\left(R_{t}=4.88 \mathrm{~min}\right)$ of the vitamin (Fig. 5B), no peaks could be observed if samples were not spiked beforehand (Fig. 5A). Linearity was demonstrated within a range of $0.1 \mu \mathrm{g} / \mathrm{mL}$ to $25 \mu \mathrm{g} / \mathrm{mL}$ for in vitro samples and $0.05 \mu \mathrm{g} / \mathrm{mL}$ to 2.5 $\mu \mathrm{g} / \mathrm{mL}$ for in vivo samples with the coefficient of determination $\left(\mathrm{R}^{2}\right)$ being 1 in both cases (Table 1 ). Additionally, inter-day and intra-day accuracy with mean recovery rates (RE) ranging between $98.49 \%$ and $100.74 \%$ and precision with a maximum relative standard deviation (RSD) of $4.32 \%$ were determined (Table 2).

\subsection{In vitro permeation study}

The in vitro delivery of vitamin B12 commenced within 2 min of MN application. After $15 \mathrm{~min}, 20.07$ $\pm 3.80 \%(30 \mu \mathrm{g})$ and after $5 \mathrm{~h}$, a total of $72.92 \pm 5.30 \%(100 \mu \mathrm{g})$ of the drug load was delivered into the receiver compartment of the Franz cell (Fig. 6). These results indicate that most MN shafts successfully pierced the skin and dissolved, thus, releasing a high percentage of their drug load.

\subsection{In vivo study}

The in vivo pharmacokinetic plasma profiles obtained after subcutaneous injection of $200 \mu \mathrm{g}$ vitamin B12 in the control animal cohort and after application of $4 \mathrm{MN}$ arrays $\left(1.44 \mathrm{~cm}^{2}\right)$, containing a total of $540 \mu \mathrm{g}$ vitamin B12, in the test cohort are presented in Fig. 7A \& 7B, respectively. These profiles were used for calculating the drug pharmacokinetic parameters reported in Table 3. In both cases, the time taken to achieve peak plasma concentrations was $30 \mathrm{~min}\left(\mathrm{~T}_{\max }\right)$. The maximum plasma concentration $\left(C_{\max }\right)$ of vitamin B12 post-subcutaneous administration was $1.30 \pm 0.25 \mu \mathrm{g} / \mathrm{mL}$ and, 
therefore, approximately 3.5 times higher than the maximum concentration of $0.37 \pm 0.04 \mu \mathrm{g} / \mathrm{mL}$ reached post-transdermal application via $\mathrm{MN}$ arrays. The mean plasma concentration dropped rapidly within $2 \mathrm{~h}$ for both dosage forms. While no drug was detectable after $24 \mathrm{~h}$ in those animals receiving the subcutaneous injection, the vitamin could still be detected in individual animals treated with $\mathrm{MN}$ arrays even after $30 \mathrm{~h}$.

The area under the curve $\left(\mathrm{AUC}_{0-30 \mathrm{~h}}\right)$ post-subcutaneous injection was $3.01 \mu \mathrm{g} / \mathrm{mL} \cdot \mathrm{h}$, whereas it was $0.81 \mu \mathrm{g} / \mathrm{mL} \cdot \mathrm{h}$ for the transdermal delivery route. Considering the dose difference between the two application forms, the relative bioavailability $\left(\mathrm{F}_{\text {rel }}\right)$ was calculated for better comparison using the following equation:

$$
\text { Frel }=\frac{A U C_{0}-30 h(M N) \cdot \operatorname{Dose}(\text { s.c. })}{A U C_{0}-30 h(\text { s.c. }) \cdot \operatorname{Dose}(M N)}
$$

The relative bioavailability was found to be 0.1 , suggesting that the amount of vitamin B12 delivered after application of $4 \mathrm{MN}$ arrays was approximately $54 \mu \mathrm{g}$.

\section{Discussion}

Transdermal drug delivery systems can improve patient compliance considerably as they have several advantages in comparison to other commonly used application forms (Kaestli et al., 2008). However, to date, only a small number of therapeutic agents are available for transdermal delivery (Szunerits \& Boukherroub, 2018). This is mainly due to the nature of skin. Its outer layer, the stratum corneum, forms a fierce barrier against external influences and only a very limited number of molecules with specific physicochemical properties (lipophilic, molecular weight $<500 \mathrm{Da}$ ) are able to pass across it. Therefore, most topically applied drugs cannot permeate through the skin to reach the underlying tissues and systemic blood circulation (Williams, 2003).

Polymeric MN arrays are a novel technology with the potential to revolutionise the prospects of transdermal drug delivery (Tekko et al., 2017). They are composed of arrays of a certain number of 
micron-sized polymeric needles. The holes created by these arrays post-application to the skin enable therapeutic agents incorporated within the arrays to bypass the stratum corneum and reach the dermal microcirculation. Several studies have shown that $M N$ arrays have the capability to increase the range of drugs that can be delivered transdermally without being affected by their physicochemical properties (González-Vázquez et al., 2017; Hutton et al., 2018; Migalska et al., 2011; McCrudden et al., 2014, 2015). Due to the short length of individual MNs, dermal nerves are not stimulated during insertion. Consequently, MNs are considered to be pain-free, minimally invasive devices. They combine the advantages of both traditional transdermal drug-delivery systems, in terms of patient compliance and the delivery capabilities of conventional hypodermic needles (Tekko et al., 2017).

It has been shown that Vitamin B12 is barely able to bypass the stratum corneum without further enhancement techniques, owing to its size (MW 1355.4 Da) (Yang et al., 2011). Therefore, the aim of this study was to develop bilayer rapidly dissolving $\mathrm{MN}$ arrays with sufficient mechanical strength for successful skin insertion and the ability to deliver a therapeutically relevant dose of vitamin B12 transdermally.

Due to its biocompatibility, non-toxicity and high water-solubility, PVP (MW $58 \mathrm{kDa}$ ) was chosen to fabricate the shafts of the dissolving $\mathrm{MN}$ arrays. This polymer is generally regarded as safe by the US Food and Drug Administration (FDA) and is widely used in injections and as a blood volume expander (Ravin et al., 1952). A further advantage is that low molecular weight PVP can be cleared by the kidneys and, therefore, does not accumulate in the body even after several applications (Ravin et al., 1952). To obtain MN baseplates with high mechanical strength, a higher molecular weight PVP (MW $360 \mathrm{kDa}$ ) was chosen. A concentration of $15 \%(\mathrm{w} / \mathrm{w})$ PVP was previously shown to form strong baseplates (Thakur et al., 2016). However, upon preparation of bilayer MN arrays using this concentration of the selected polymer, considerable amounts of vitamin B12 migrated from MN shafts into baseplates. As one of the aims of this study was to concentrate vitamin B12 into the MN 
shafts only, the amount of PVP used for baseplate fabrication was subsequently increased to $50 \%$. Consequently, diffusion of drug from MN shafts into the baseplate was prevented and two clearly separated layers, namely MN shafts and baseplate were formed.

The formulation of bilayer MN arrays has many advantages. Different characteristics for MN shafts and baseplates, in terms of mechanical strength and dissolution kinetics can be achieved.

Furthermore, the location of the therapeutic agent into the shafts only, leads to a reduction in drug waste. This is especially beneficial in scale-up processes and for highly expensive agents. For the preparation of bilayer MN arrays, different techniques have been performed previously (Fukushima et al., 2011; Ling et al., 2013; Zaric et al., 2013; Wang et al., 2015; McCaffrey et al., 2016; GonzálezVázquez et al., 2017; Vora et al., 2017). While González-Vázquez et al. (2017) placed a pre-formed baseplate onto cast MN shafts, Vora et al. (2017) prepared a suspension containing nanoparticles and then concentrated them into MN shafts by high speed centrifugation. As these methods were not applicable in the present study, a new technique was developed for forming two different layers.

The fabricated bilayer $\mathrm{MN}$ arrays were characterised in vitro in terms of their mechanical strength, insertion into skin, dissolution kinetics in skin, and their capability to deliver their drug load in in vitro and in vivo settings. Although, compressing $\mathrm{MN}$ arrays against an aluminium block using a texture analyser is not similar to $\mathrm{MN}$ insertion into skin, this test is a widely accepted method for evaluating their mechanical strength (McCrudden et al., 2014; Thakur et al., 2016; Ripolin et al., 2017). In the present study, a constant force of $32 \mathrm{~N}$ per array was applied for $30 \mathrm{~s}$ as this equates to the force used by humans for successful insertion of MN arrays (Larrañeta et al., 2014). The calculated reduction of $M N$ shaft heights was minimal $(2.5 \pm 2 \%, n=6)$. Previous studies showed that $M N$ arrays which encountered up to $20 \%$ reduction in height were still successfully inserted into skin in in vitro and in vivo settings (McCrudden et al., 2014; Thakur et al., 2016; Ripolin et al., 2017). Therefore, the obtained test results indicate that the fabricated $\mathrm{MN}$ arrays have sufficient mechanical strength for insertion into human skin. Additionally, they inserted excellently into an artificial skin simulant 
consisting of Parafilm $\mathrm{M}^{\circledast}$ (Larrañeta et al. 2014). Application of $\mathrm{MN}$ arrays to neonatal porcine skin, a widely accepted model for human skin, demonstrated the desired rapid dissolution of the needle shafts in vitro. More than $50 \%$ of MN shafts dissolved within $30 \mathrm{~s}$ of application, with all shafts dissolved after only $2 \mathrm{~min}$, thus reducing application time to a minimum. These results agree with data previously obtained by Thakur et al. (2016) who reported a dissolution time of 3 min in ocular tissues for the same polymer. Before carrying the developed bilayer MN arrays forward to an in vivo study, the ability to deliver vitamin B12 through neonatal porcine skin was demonstrated in vitro using Franz-cells. More than $70 \%$ of the incorporated drug load was released within $5 \mathrm{~h}$.

The in vivo study clearly demonstrated that the fabricated bilayer MN arrays can deliver vitamin B12 transdermally in a minimally invasive way. Upon removal of the $\mathrm{MN}$ array patches, $\mathrm{MN}$ shafts were completely dissolved and no erythema was observed at the application site. Any remaining baseplates could be easily wiped off the skin with a wet cloth. Maximum blood levels were reached within 30 min post-application of the patches to the back of the animals. It should be noted, that the $\mathrm{AUC}_{0-30 \mathrm{~h}}$ after subcutaneous injection was 3.7 times higher compared to $\mathrm{MN}$ application, even though the applied patches contained 2.7 times more drug. However, this can be explained by the fact that only the inserted part of MN shafts (63.5\% in in vitro settings) would be expected to release their drug load. Considering that vitamin B12 is commonly applied intramuscularly or subcutaneously, the AUC post-subcutaneous injection can be assumed to present the maximal delivery possible. Under this assumption, the relative bioavailability of vitamin B12 from MN patches was calculated to be 0.1 compared to subcutaneous delivery. The amount of vitamin delivered transdermally with a patch size of $1.44 \mathrm{~cm}^{2}$ was therefore approximately $54 \mu \mathrm{g}$.

This study represents a proof of concept for the feasibility of using rapidly dissolving $\mathrm{MN}$ arrays for transdermal delivery of vitamin B12. Predicting pharmacokinetics in humans on the basis of animal studies requires further investigation, especially as pharmacokinetic results for elderly people presented by Tillemans et al. (2014) demonstrated considerable differences compared to results 
obtained in the present study. Nevertheless, the patch size necessary to deliver therapeutically relevant amounts of vitamin B12 can be cautiously extrapolated from the data presented here. Considering that a patch sized $1.44 \mathrm{~cm}^{2}$ delivered approximately $54 \mu \mathrm{g}$, a patch size of approximately $27 \mathrm{~cm}^{2}$ might be sufficient to deliver the commonly applied dose of $1000 \mu \mathrm{g}$. This area could be reduced by increasing the drug load within the MN arrays. As vitamin B12 is only sparingly water soluble, formulating a nanosuspension prior to casting $\mathrm{MN}$ arrays is also a possible approach (Vora et al., 2018; McCrudden et al., 2018). Although there are considerable inherent differences between MN patches and currently marketed transdermal patches, relatively big patches are generally accepted by patients. Even without further reduction in the MN patch size determined here, the calculated area of $27 \mathrm{~cm}^{2}$ is well within the range of available transdermal patches, with Nicotinell ${ }^{\circledast}$ (nicotine) patches measuring $30 \mathrm{~cm}^{2}$ (Novartis, 2018) and Duragesic ${ }^{\circledR} \mathrm{Cll}$ (fentanyl) patches measuring 32 and $42 \mathrm{~cm}^{2}$ (Janssen, 2018). MN patches sized up to $25 \mathrm{~cm}^{2}$ have already been prepared previously (Donnelly et al., 2012) and the successful application of large patches by human volunteers has been shown (Ripolin et al., 2017). Therefore, even though further investigations are required, the results obtained in this study show the potential of delivering clinically relevant doses of vitamin B12 using dissolving polymeric MN arrays.

\section{Conclusion}

This study reports the successful incorporation of vitamin B12 into bilayer dissolving polymeric MN arrays. Moreover, it demonstrates that the transdermal delivery of a therapeutically relevant dose of vitamin B12 in vivo within a short period of time is feasible by using these novel devices. This highlights the promising impact this minimally invasive technology could have on the future treatment of vitamin B12 deficiency caused by malabsorption. Further studies are required however before MN arrays can be successfully taken forward for the potential treatment of vitamin B12 deficiency. Specifically, the design, formulation and fabrication of larger MN patches; up-scaling the manufacture of MN arrays in an economically viable way and the introduction of standardised 
mechanical and characterisation tests for $\mathrm{MN}$ arrays are all necessitated before this drug delivery platform can be used to effectively treat those people affected by vitamin B12 deficiency.

\section{References}

E. Andrès, N.H. Loukili, E. Noel, G. Kaltenbach, M.B. Abdelgheni, A.E. Perrin, M. Noblet-Dick, F. Maloisel, J.L. Schlienger, J.F. Blicklé, Vitamin B12 (cobalamin) deficiency in elderly patients, CMAJ 171 (2004) 251-259, https://doi.org/10.1503/cmaj.1031155.

L.H. Allen, How common is vitamin B-12 deficiency?, Am. J. Clin. Nutr. 89 (2009) 693S-696S, https://doi.org/10.3945/ajcn.2008.26947A.

B. de Benoist, Conclusions of a WHO Technical Consultation on folate and vitamin B12 deficiencies, Food Nutr. Bull. 29 (2008) S238-S244, https://doi.org/10.1177/15648265080292S129.

V. Devalia, M.S. Hamilton, A.M. Molloy, Guidelines for the diagnosis and treatment of cobalamin and folate disorders, Br. J. Haematol. 166 (2014) 496-513, https://doi.org/10.1111/bjh.12959.

R.F. Donnelly, T.R.R. Singh, M.J. Garland, K. Migalska, R. Majithiya, C.M. McCrudden, P.L. Kole, T.M.T. Mahmood, H.O. McCarthy, A.D. Woolfson, Hydrogel-forming microneedle arrays for enhanced transdermal drug delivery, Adv. Funct. Mater. 22 (2012) 4879-4890, https://doi.org/10.1002/adfm.201200864.

C. Edens, M.L. Collins, J.L. Goodson, P.A. Rota, M.R. Prausnitz, A microneedle patch containing measles vaccine is immunogenic in non-human primates, Vaccine 33 (2015) 4712-4718, http://dx.doi.org/10.1016/j.vaccine.2015.02.074.

K. Fukushima, A. Ise, H. Morita, R. Hasegawa, Y. Ito, N. Sugioka, K. Takada, Two-layered dissolving microneedles for percutaneous delivery of peptide/protein drugs in rats, Pharm. Res. 28 (2011) 721, http://dx.doi.org/10.1007/s11095-010-0097-7. 
M.J. Garland, K. Migalska, T.-M. Tuan-Mahmood, T.R.R. Singh, R. Majithija, E. Caffarel-Salvador, C.M. McCrudden, H.O. McCarthy, A.D. Woolfson, R.F. Donnelly, Influence of skin model on in vitro performance of drug-loaded soluble microneedle arrays, Int. J. Pharm. 434 (2012) 80-89, http://dx.doi.org/10.1016/j.jpharm.2012.05.069.

P. González-Vázquez, E. Larrañeta, M.T.C. McCrudden, C. Jarrahian, A. Rein-Weston, M. QuintanarSolares, D. Zehrung, H. McCarthy, A.J. Courtenay, R.F. Donnelly, Transdermal delivery of gentamicin using dissolving microneedle arrays for potential treatment of neonatal sepsis, J. Control. Release 265 (2017) 30-40, http://dx.doi.org/10.1016/j.jconrel.2017.07.032.

T. Guney, A.S. Yikilmaz, I. Dilek, Epidemiology of vitamin B12 deficiency, Epidemiology of Communicable and Non-Communicable Diseases, IntechOpen (2016) 103-112, http://dx.doi.org/10.5772/63760.

A.R.J. Hutton, H.L. Quinn, P.J. McCague, C. Jarrahian, A. Rein-Weston, P.S. Coffey, E. Gerth-Guyette, D. Zehrung, E. Larrañeta, R.F. Donnelly, Transdermal delivery of vitamin K using dissolving microneedles for the prevention of vitamin K deficiency bleeding, Int. J. Pharm. 541 (2018) 56-63, https://doi.org/10.1016/j.ijpharm.2018.02.031.

Janssen, 2018. Duragesic Website. http://www.duragesic.com/. (Accessed 1 July 2018).

International Conference on Harmonisation of Technical Requirements for Registration of Pharmaceuticals for Human Use, ICH harmonised tripartite guideline, Validation of analytical procedures: Text and methodology Q2(R1) (2005).

Institute of Medicine, Dietary reference intakes for thiamine, riboflavin, niacin, vitamin B6, folate, vitamin B12, panthotenic acid, biotine and choline, Washington (DC), National Academies Press (1998), https://doi.org/10.17226/6015. 
L.-Z. Kaestli, A.-F. Wasilewski-Rasca, P. Bonnabry, N. Vogt-Ferrier, Use of transdermal drug formulations in the elderly, Drugs Aging 25 (2008) 269-280.

C. Lachner, N.I. Steinle, W.T. Regenold, The neuropsychiatry of vitamin B12 deficiency in elderly patients, J. Neuropsychiatry Clin. Neurosci. 24 (2012) 5-15, https://doi.org/10.1176/appi.neuropsych.11020052.

E. Larrañeta, R.E.M. Lutton, A.D. Woolfson, R.F. Donnelly, Microneedle arrays as transdermal and intradermal drug delivery systems: materials science, manufacture and commercial development, Mater. Sci. Eng. R. Rep. 104 (2016) 1-32, http://dx.doi.org/10.1016/j.mser.2016.03.001.

E. Larrañeta, J. Moore, E.M. Vicente-Pérez, P. González-Vázquez, R. Lutton, A.D. Woolfson, R.F. Donnelly, A proposed model membrane and test method for microneedle insertion studies, Int. J. Pharm. 472 (2014) 65-73, http://dx.doi.org/10.1016/j.ijpharm.2014.05.042.

M.-H. Ling, M.-C. Chen, Dissolving polymer microneedle patches for rapid and efficient transdermal delivery of insulin to diabetic rats, Acta Biomater. 9 (2013) 8952-8961, http://dx.doi.org/10.1016/j.actbio.2013.06.029.

K. Matsuo, S. Hirobe, Y. Yokota, Y. Ayabe, M. Seto, Y.S. Quan, F. Kamiyama, T. Tougan, T. Horii, Y. Mukai, N. Okada, S. Nakagawa, Transcutaneous immunization using a dissolving microneedle array protects against tetanus, diphtheria, malaria and influenza, J. Control. Release 160 (2012) 495-501, http://dx.doi.org/10.1016/j.jconrel.2012.04.001.

J. McCaffrey, C.M. McCrudden, A.A. Ali, A.S. Massey, J.W. McBride, M.T.C. McCrudden, E.M. VicentePerez, J.A. Coulter, T. Robson, R.F. Donnelly, H.O. McCarthy, Transcending epithelial and intracellular biological barriers; a prototype DNA delivery device, J. Control. Release 226 (2016) 238-247, http://dx.doi.org/10.1016/j.jconrel.2016.02.023. 
M.T.C. McCrudden, A.Z. Alkilani, C.M. McCrudden, E. McAlister, H.O. McCarthy, A.D. Woolfson, R.F. Donnelly, Design and physicochemical characterisation of novel dissolving polymeric microneedle arrays for transdermal delivery of high dose, low molecular weight drugs, J. Control. Release 180 (2014) 71-80, http://dx.doi.org/10.1016/j.jconrel.2014.02.007.

M.T.C. McCrudden, B.M. Torrisi, S. Al-Zahrani, C.M. McCrudden, M. Zaric, C.J. Scott, A. Kissenpfennig, H.O. McCarthy, R.F. Donnelly, Laser-engineered dissolving microneedle arrays for protein delivery: potential for enhanced intradermal vaccination, J. Pharm. Pharmacol. 67 (2015) 409-425, http://dx.doi.org/10.1111/jphp.12248.

M.T.C. McCrudden, E. Larrañeta, A.Clark, C. Jarrahian, A. Rein-Weston, S. Lachau-Durand, N. Niemeijer, P. Williams, C. Haeck, H.O. McCarthy, D. Zehrung, R.F. Donnelly, Design, formulation and evaluation of novel dissolving microarray patches containing a long-acting rilpivirine nanosuspension, J. Control. Release 292. (2018) 119-129, https://doi.org/10.1016/j.jconrel.2018.11.002.

K. Migalska, D.I.J. Morrow, M.J. Garland, R. Thakur, A.D. Woolfson, R.F. Donnelly, Laser-engineered dissolving microneedle arrays for transdermal macromolecular drug delivery, Pharm. Res. 28 (2011) 1919-1930, http://dx.doi.org/10.1007/s11095-011-0419-4.

Novartis, 2018. Nicotinell Website. http://www.nicotinell.co.uk/. (Accessed 1 July 2018).

S. Ogston-Tuck, Intramuscular injection technique: an evidence-based approach, Nursing Standard 29 (2014) 52-59.

M.R. Pepper, M.M. Black, B12 in fetal development, Semin. Cell. Dev. Biol. 22 (2011) 619-623, https://doi.org/10.1016/j.semcdb.2011.05.005. 
H.L. Quinn, C.M. Hughes, R.F. Donnelly, In vivo and qualitative studies investigating the translational potential of microneedles for use in the older population, Drug Deliv. Transl. Res. 8 (2018) 307-316, https://doi.org/10.1007/s13346-017-0393-4.

H.A. Ravin, A.M. Seligman, J. Fine, Polyvinyl pyrrolidone as a plasma expander; studies on its excretion, distribution and metabolism, N. Engl. J. Med. 247 (1952) 921-929, Epub 1952/12/11.

A. Ripolin, J. Quinn, E. Larrañeta, E.M. Vicente-Perez, J. Barry, R.F. Donnelly, Successful application of large microneedle patches by human volunteers, Int. J. Pharm. 521 (2017) 92-101, http://dx.doi.org/10.1016/j.ijpharm.2017.02.011.

S. Szunerits, R. Boukherroub, Heat: A highly efficient skin enhancer for transdermal drug delivery, Front. Bioeng. Biotechnol. 6:15 (2018), https://doi.org/10.3389/fbioe.2018.00015.

S.P. Sullivan, D.G. Koutsonanos, M. del Pilar Martin, J.W. Lee, V. Zarnitsyn, S.O. Choi, N. Murthy, R.W. Compans, I. Skountzou, M.R. Prausnitz, Dissolving polymer microneedle patches for influenza vaccination, Nat. Med. 16 (2010) 915-920, http://dx.doi.org/10.1038/nm.2182.

A. Summerfield, F. Meurens, M.E. Ricklin, The immunology of the porcine skin and its value as a model for human skin, Mol. Immunol. 66 (2015) 14-21, http://dx.doi.org/10.1016/j.molimm.2014.10.023.

I.A. Tekko, E. Larrañeta, A.M. Rodgers, C.J. Scott, A. Kissenpfennig, R.F. Donnelly, Microneedles in nanomedicine delivery (subchapter), in "Nanotechnologies for tissue engineering and regeneration", V. Uskokovic, editor. Nanotechnologies in Preventive and Regenerative Medicine: An Emerging Big Picture. Elsevier (2017):p131- 163.

R.R.S. Thakur, I.A. Tekko, F. Al-Shammari, A.A. Ali, H. McCarthy, R.F. Donnelly, Rapidly dissolving polymeric microneedles for minimally invasive intraocular drug delivery, Drug Deliv. Transl. Res. 6 (2016) 800-815, http://dx.doi.org/10.1007/s13346-016-0332-9. 
M.P.H. Tillemans, E.M.V.J. Donders, S.L. Verweij, R.T.M. Van der Hoeven, K.J. Kalisvaart, Effect of Administration Route on the Pharmacokinetics of Cobalamin in Elderly Patients: A Randomized Controlled Trial, Curr. Ther. Res. Clin. Exp. 76 (2014) 21-25, http://dx.doi.org/10.1016/j.curtheres.2014.01.001.

United Nations, Department of Economic and Social Affairs, Population Division, World Population Prospects: The 2017 Revision, Key Findings and Advance Tables, ESA/P/WP/248 (2017).

J. Vidal-Alaball, C. Butler, R. Cannings-John, A. Goringe, K. Hood, A. McCaddon, I. McDowell, A. Papaioannou, Oral vitamin B12 versus intramuscular vitamin B12 for vitamin B12 deficiency, Cochrane Database Syst Rev. 3 (2005) CD004655, http://dx.doi.org/10.1002/14651858.CD004655.pub2.

B.Y. Vigbedor, N.A.O. Nathaniel, R.K. Adosraku, O.A. Samuel, Design of HPLC method for quantification of cyanocobalamin injection, IJNRLS 2 (2015) 26-39.

L.K. Vora, R.F. Donnelly, E. Larrañeta, P. González-Vázquez, R.R.S. Thakur, P.R. Vavia, Novel bilayer dissolving microneedle arrays with concentrated PLGA nano-microparticles for targeted intradermal delivery: Proof of concept, J. Control. Release 265 (2017) 93-101, http://dx.doi.org/10.1016/j.jconrel.2017.10.005.

L. K. Vora, P. R. Vavia, E. Larrañeta, S. E. Bell, R. F. Donnelly, Novel nanosuspension-based dissolving microneedle arrays for transdermal delivery of a hydrophobic drug, Journal of Interdisciplinary Nanomedicine 3 (2018) 89-101.

Q. Wang, G. Yao, P. Dong, Z. Gong, G. Li, K. Zhang, C. Wu, Investigation on fabrication process of dissolving microneedle arrays to improve effective needle drug distribution, Eur. J. Pharm. Sci. 66 (2015) 148-156, http://dx.doi.org/10.1016/j.ejps.2014.09.011. 
A. Williams, Transdermal and topical drug delivery: from theory to clinical practice. London: Pharmaceutical Press (2003).

Y. Yang, H. Kalluri, A.K. Banga, Effects of chemical and physical enhancement techniques on transdermal delivery of cyanocobalamin (vitamin B12) in vitro, Pharmaceutics 3 (2011) 274-484, https://doi.org/10.3390/pharmaceutics3030474.

M. Zaric, O. Lyubomska, O. Touzelet, C. Poux, S. Al-Zahrani, F. Fay, L. Wallace, D. Terhorst, B. Malissen, S. Henri, U.F. Power, C.J. Scott, R.F. Donnelly, A. Kissenpfennig, Skin dendritic cell targeting via microneedle arrays laden with antigen-encapsulated poly-d,I-lactide-co-glycolide nanoparticles induces efficient antitumor and antiviral immune responses, ACS Nano 7 (2013) 2042-2055, http://dx.doi.org/10.1021/nn304235j. 


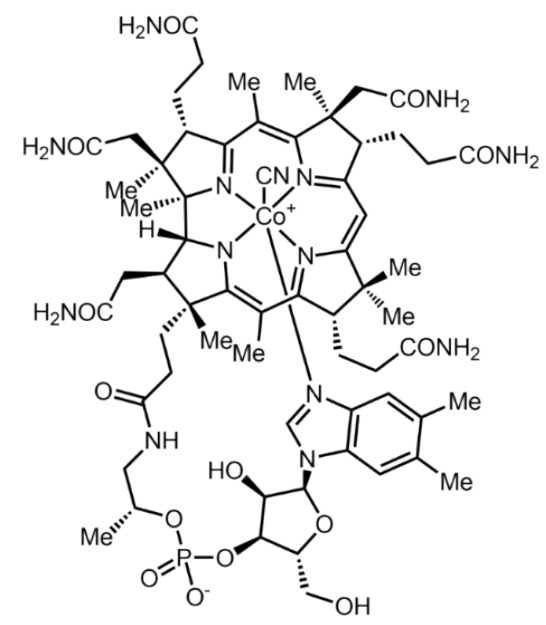

Figure 1. Chemical structure of cyanocobalamin.
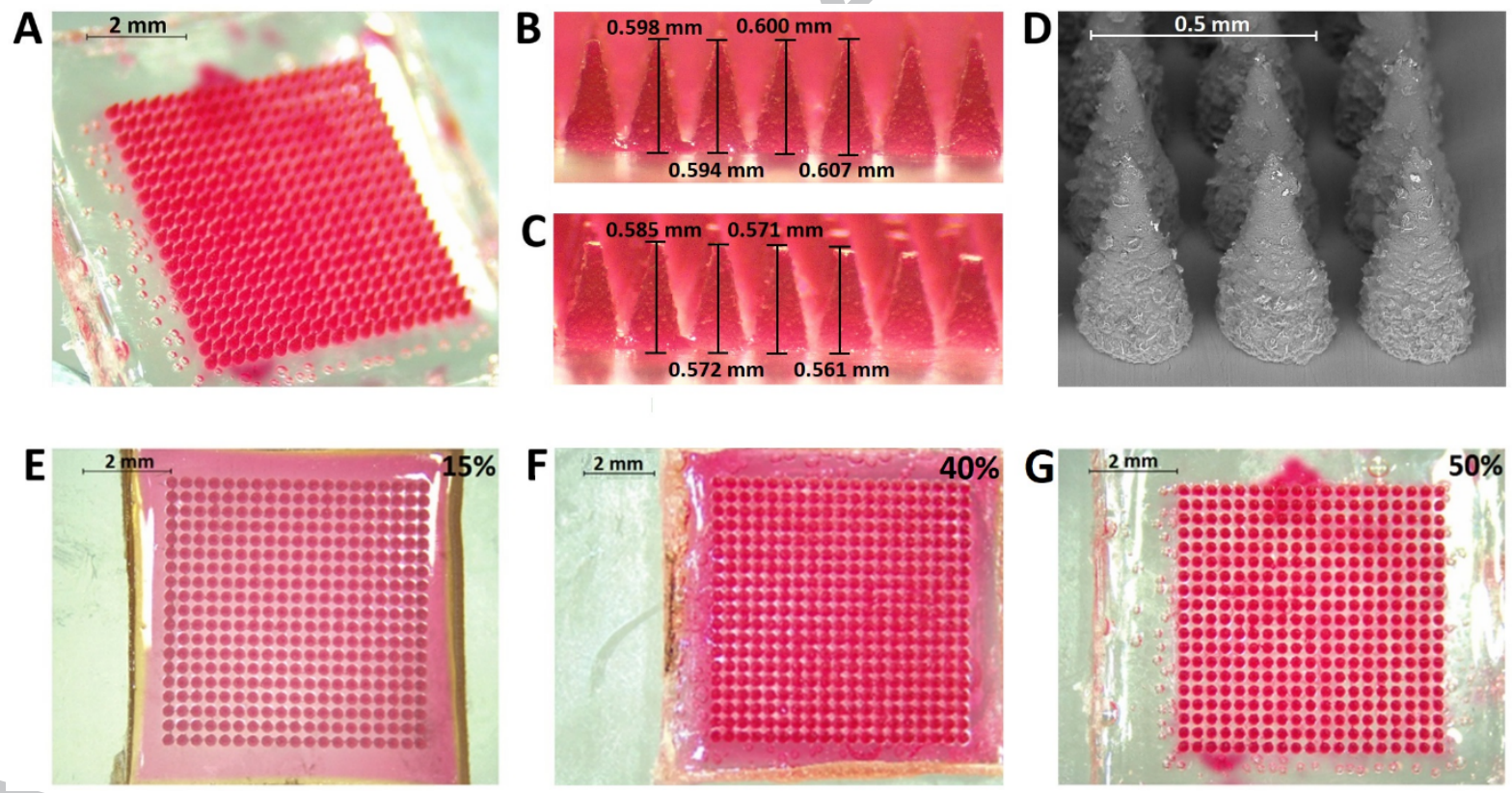

Figure 2. (A) Light microscope image (10x) of a dissolving bilayer MN array with vitamin B12 incorporated only into the needle shafts. The array was cast using a mould with 361 conical shaped needles (19 x 19), measuring $600 \mu \mathrm{m}$ in height and $300 \mu \mathrm{m}$ at base. (B) Light microscope image (35x) showing MN shaft height measurements of a MN array before compression. (C) Light microscope image (35x) showing MN shaft height measurements after compression (32 N/array, $30 \mathrm{~s}$ ). (D) Scanning electron microscope image (150x) displaying surface characteristics of MN shafts. (E-G) Light microscope images of bilayer MN arrays with three different baseplates cast out of hydrogels made from aqueous blends containing 15\% (w/w) (E), 40\% (w/w) (F) and 50\% (w/w) PVP (MW 360 kDa) (G), respectively. 


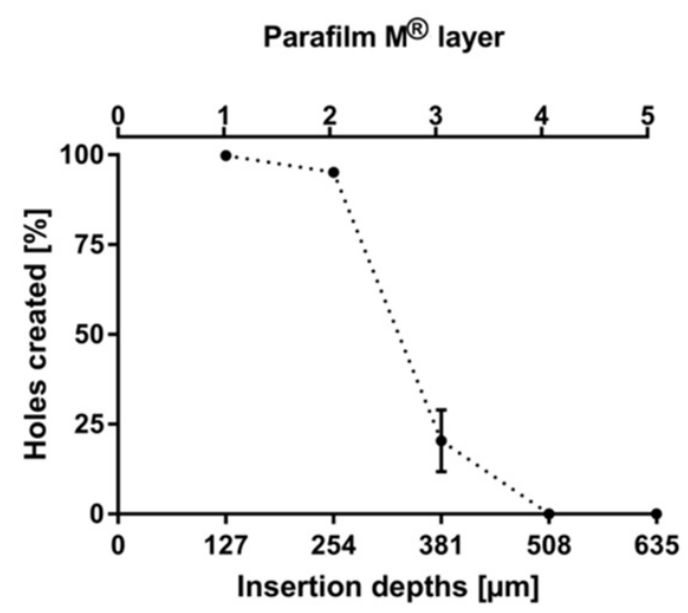

Figure 3. Percentage holes created in each Parafilm $M^{\circledR}$ layer (means $\pm S D, n=3$ ) by insertion of $M N$ arrays with 361 needles of $600 \mu \mathrm{m}$ heights into the Parafilm $\mathrm{M}^{\circledast}$ skin simulant.
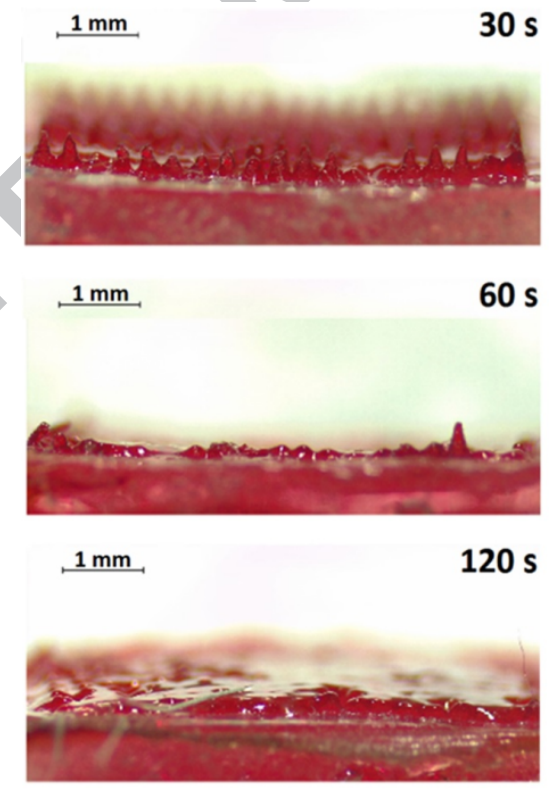

Figure 4. Light microscope images of $\mathrm{MN}$ arrays following insertion into neonatal porcine skin and removal after predetermined time periods of $30 \mathrm{~s}, 60 \mathrm{~s}$ and $120 \mathrm{~s}$. 

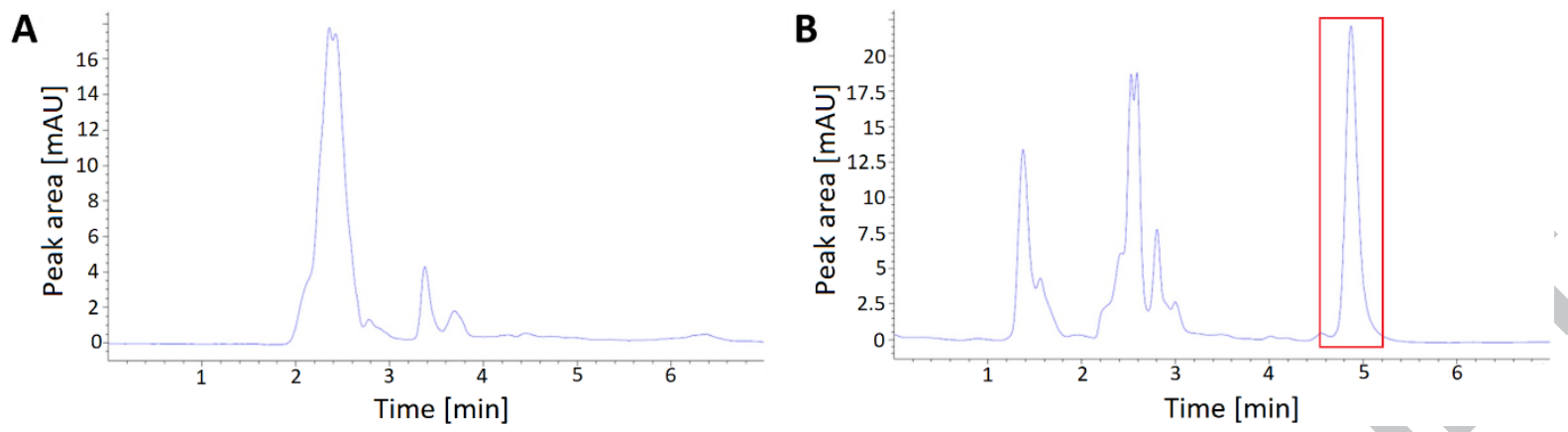

Figure 5. HPLC chromatograms after injecting (A) blank rat plasma and (B) a sample prepared from rat plasma spiked with $2.5 \mu \mathrm{g} / \mathrm{mL}$ vitamin $\mathrm{B} 12\left(\mathrm{R}_{\mathrm{t}}=4.88 \mathrm{~min}\right.$, highlighted in red box).

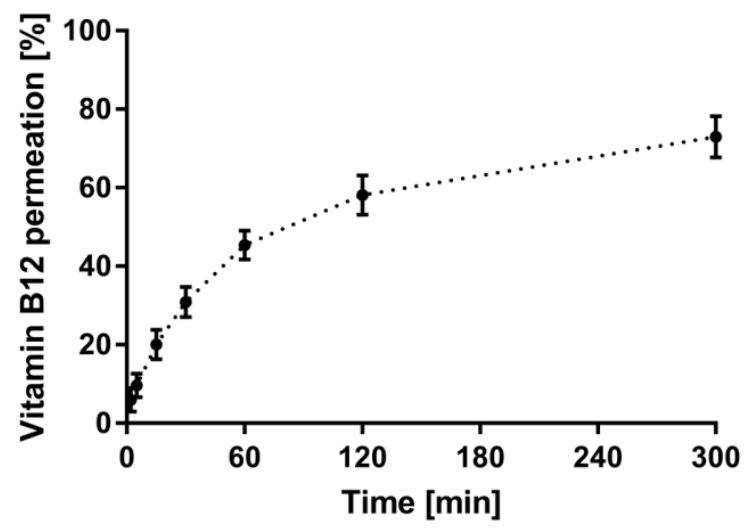

Figure 6. In vitro permeation profile of vitamin B12 through dermatomed neonatal porcine skin (means \pm SD, $n$ =3).
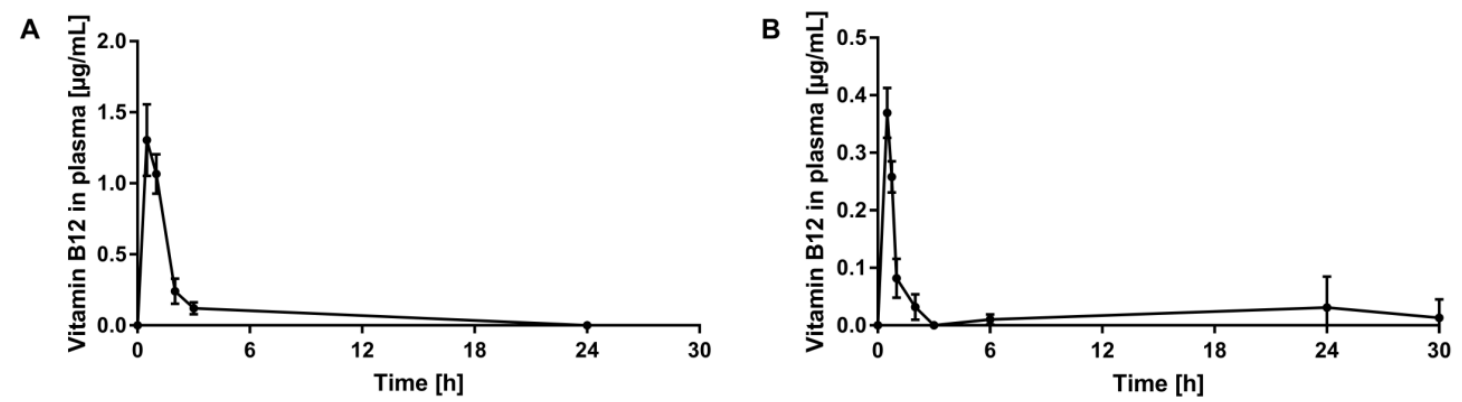

Figure 7. (A) In vivo plasma profile of vitamin B12 after subcutaneous injection of $200 \mu \mathrm{L}$ aqueous vitamin B12 solution $(200 \mu \mathrm{g}$ ) (means $\pm \mathrm{SD}, \mathrm{n}=3$ at $0.5,1,2,3 \mathrm{~h}$ and $\mathrm{n}=6$ at $24 \mathrm{~h}$ ). (B) In vivo plasma profile of vitamin B12 after application of $4 \mathrm{MN}$ arrays containing a total of $540 \mu \mathrm{g}$ vitamin B12 (means $\pm S D, n=2$ at $3 \mathrm{~h}, \mathrm{n}=3$ at 0.5 , $0.75,1,2,6 \mathrm{~h}$ and $\mathrm{n}=6$ at $24,30 \mathrm{~h})$. 


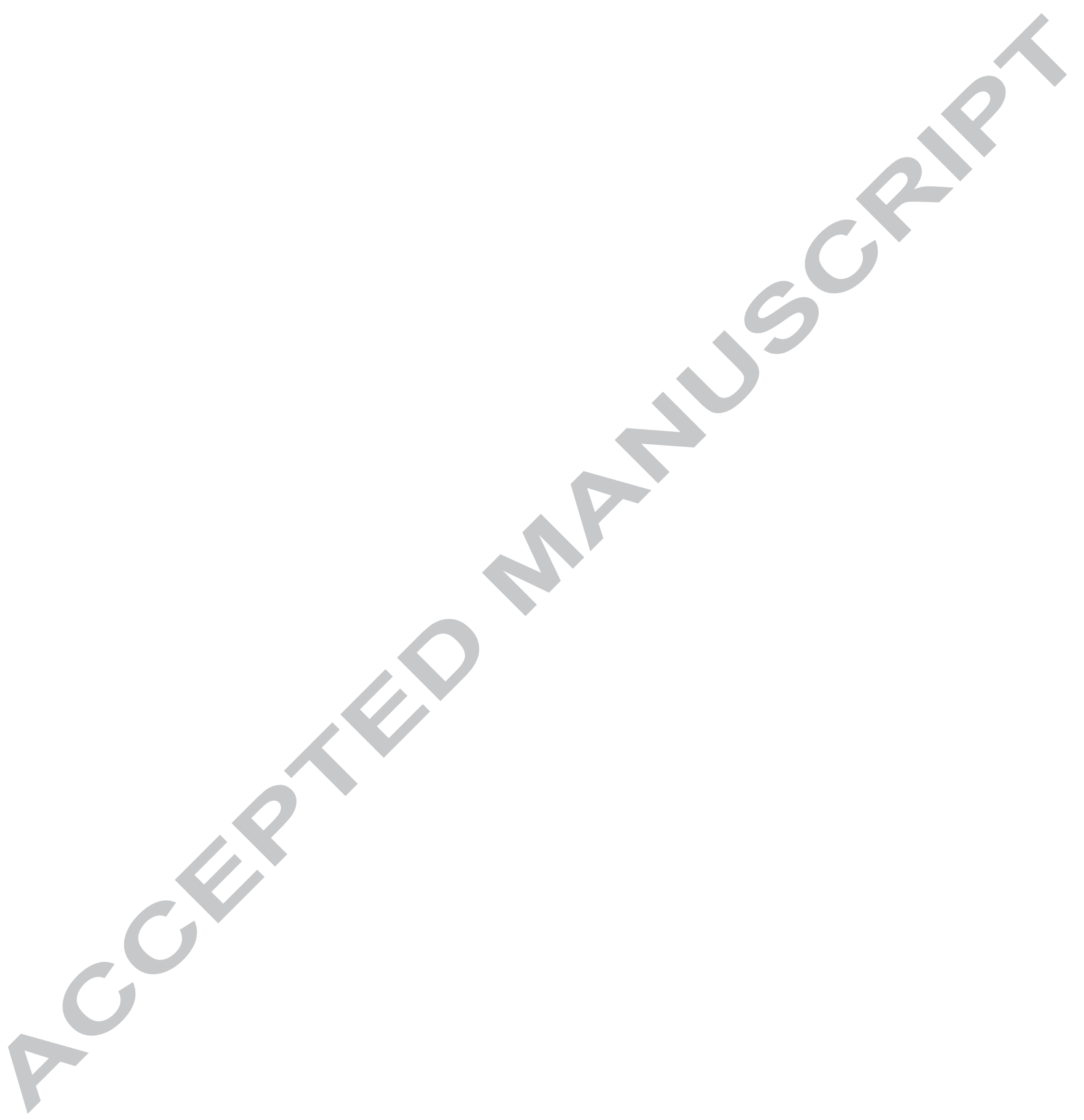


Table 1. Summary of the calibration parameters for HPLC analysis of vitamin B12 in in vitro and in vivo sample matrices. Presented are slopes, $y$-intercepts, coefficients of determination $\left(R^{2}\right)$, ranges, limits of quantification (LOQ) and limits of detection (LOD).

\begin{tabular}{l|cccccc} 
& Slope & y-Intercept & $\mathbf{R}^{2}$ & Range $[\mu \mathrm{g} / \mathrm{mL}]$ & LOQ $[\mu \mathrm{g} / \mathrm{mL}]$ & LOD $[\mu \mathrm{g} / \mathrm{mL}]$ \\
\hline In vitro & 33.315 & -0.5109 & 1 & $0.1-25$ & 0.049 & 0.016 \\
In vivo & 101.07 & -0.4411 & 1 & $0.05-2.5$ & 0.038 & 0.012
\end{tabular}

Table 2. Summary of the inter-day and intra-day accuracy and precision of HPLC analysis of vitamin B12 in in vitro and in vivo sample matrices as represented by theoretical concentrations $\left(C_{T}\right)$ covering the range of the methods, calculated concentrations $\left(C_{c}\right.$, means $\left.\pm S D, n=3\right)$, percentage recoveries $(R E)$ and relative standard deviations (RSD).

\begin{tabular}{c|c|ccc|ccc}
\multicolumn{2}{c|}{} & \multicolumn{4}{|c}{ Inter-day } & \multicolumn{3}{c}{ Intra-day } \\
\hline \multirow{3}{*}{ In vitro } & $\mathrm{C}_{\mathrm{T}}[\mu \mathrm{g} / \mathrm{mL}]$ & $\mathrm{C}_{\mathrm{C}}[\mu \mathrm{g} / \mathrm{mL}]$ & $\mathrm{RE}[\%]$ & $\mathrm{RSD}[\%]$ & $\mathrm{C}_{\mathrm{c}}[\mu \mathrm{g} / \mathrm{mL}]$ & $\mathrm{RE}[\%]$ & $\mathrm{RSD}[\%]$ \\
& 1 & $1.01 \pm 0.03$ & 100.59 & 3.32 & $0.98 \pm 0.04$ & 98.49 & 4.32 \\
& 10 & $10.00 \pm 0.05$ & 100.04 & 0.45 & $10.00 \pm 0.01$ & 99.96 & 0.10 \\
\hline \multirow{3}{*}{ In vivo } & 20 & $19.90 \pm 0.36$ & 99.50 & 1.81 & $20.15 \pm 0.03$ & 100.74 & 0.14 \\
& 1 & $0.99 \pm 0.03$ & 98.49 & 3.05 & $1.00 \pm 0.01$ & 99.61 & 1.05 \\
& 2 & $1.99 \pm 0.04$ & 100.45 & 1.95 & $2.01 \pm 0.00$ & 100.35 & 0.13
\end{tabular}

Table 3. Pharmacokinetic parameters for vitamin B12 obtained in rats after subcutaneous (s.c.) injection or application of $4 \mathrm{MN}$ arrays. Parameters displayed are area under the curve $\left(\mathrm{AUC}_{0-30} \mathrm{~h}\right)$, peak plasma concentration $\left(C_{\max }\right.$, means $\pm S D, n=3$ ) and time to peak plasma concentration $\left(T_{\max }\right)$.

\begin{tabular}{l|cc} 
& s.c. & MN \\
\hline $\mathrm{AUC}_{0-30 \mathrm{~h}}[\mu \mathrm{g} / \mathrm{mL} \cdot \mathrm{h}]$ & 3.01 & 0.81 \\
$\mathrm{C}_{\max }[\mu \mathrm{g} / \mathrm{mL}]$ & $1.30 \pm 0.25$ & $0.37 \pm 0.04$ \\
$\mathrm{~T}_{\max }[\mathrm{min}]$ & 30 & 30
\end{tabular}




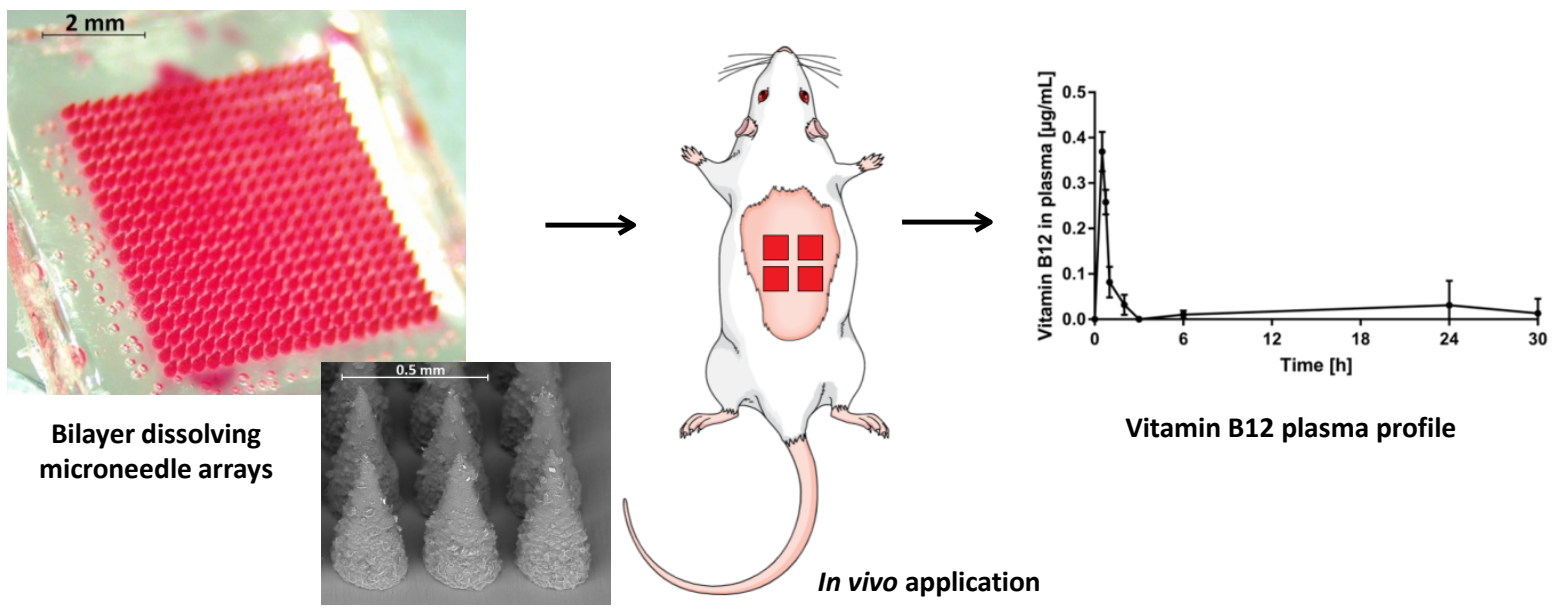




\section{Declaration of interests}

$\bigotimes$ The authors declare that they have no known competing financial interests or personal relationships that could have appeared to influence the work reported in this paper.

$\square$ The authors declare the following financial interests/personal relationships which may be considered as potential competing interests: 